For Debate . . .

\title{
Developmental paediatrics in primary care: what should we teach?
}

\author{
GILLIAN BAIRD, D M B HALL
}

\begin{abstract}
There is little agreement about what constitutes good developmental paediatric practice at the level of primary care. Many of the available screening tests are intrinsically unsatisfactory or badly performed, but screening is only a small part of developmental paediatrics. Every primary care doctor should be familiar with the scientific basis of the subject even if a decision is made not to embark on a formal screening programme.
\end{abstract}

\section{Introduction}

The term developmental paediatrics encompasses the study and promotion of optimum physical and mental health in childhood. More specifically, it covers the evolution of motor, mental, sensory, and emotional functions together with the detection, investigation, and management of children in whom the development of these functions is suspect or abnormal.

In response to an increasing demand over the past five years we have organised several courses in developmental paediatrics for trainees in general practice and clinical medical officers. In planning our curriculum we have realised that there is remarkably little agreement about what constitutes good developmental paediatrics at the level of primary care. There is more agreement about the aims, which are to detect important problems affecting development at an early stage as efficiently as possible; to respond appropriately when such problems are detected; and to ensure that subsequent counselling and support are adequate. This paper considers how these aims can be achieved.

Although developmental paediatrics has benefited less from the technological advances of medicine than many other specialties, important progress has been made in the past decade. Parents find it easier to obtain expert advice, counselling has improved, and diagnosis is more precise. It is now rare for a serious handicap to be diagnosed at school age, and parents usually have several years in which to come to terms with the educational implications of handicap. Unfortunately, in the minds of many doctors developmental paediatrics has become synonymous with developmental screening, which they see as a sterile, mechanistic exercise of ritual testing and box ticking. These misgivings have some validity; few developmental tests satisfy all the classic criteria for screening tests laid down by Wilson and Jungner, ${ }^{1}$ Cochrane and Holland, ${ }^{2}$ and Rose. ${ }^{3}$ It is impossible to assess the overall value of developmental screening as it incorporates a variety of individual test procedures, each of which requires critical evaluation. This should be a top priority for general practice research; little progress has been made since Holt reviewed the subject 11 years ago. ${ }^{+}$

Newcomen Centre, Guy's Hospital, London SE1

GILLIAN BAIRD, MRCP, DCH, consultant paediatrician

St George's Hospital, London SW17

D M B HALL, MRCP, consultant and senior lecturer in paediatrics

Correspondence to: Dr Hall

\section{Definitions}

In this paper developmental surveillance means all activities related to the detection of developmental problems at the level of primary care together with preventive measures such as immunisation and education of parents. Developmental screening means the process of methodically checking the development of children whose parents believe them to be normal. Screening is merely one of the many tools available in developmental surveillance. Taking the appropriate action when parents suspect an abnormality is an important part of developmental surveillance but is not screening.

The terms impairment (or defect), disability, and handicap are widely used in developmental paediatrics, and there is an important philosophical distinction between them. ${ }^{5}$ An impairment is an anatomical or physiological abnormality; a disability refers to the functional effect of the impairment; and handicap implies that the disability prevents or hinders attainment of socially desirable roles and behaviour. Personality and social factors often determine whether a particular impairment or disability results in handicap. These terms cannot, however, be directly related to the various types of developmental problem, and we have therefore used the following classification. Major handicap includes conditions that almost inevitably have a major effect on the child's life-that is, severe mental handicap with intelligence quotient (IQ) less than 50, cerebral palsy, spina bifida, serious orthopaedic disorders, sensorineural hearing loss, the rare aphasias, and partial or total blindness. Minor defects are less serious but nevertheless important organic conditions and include minor hearing losses due to disease of the middle ear, squint, refractive errors, amblyopia, and minor orthopaedic anomalies. Developmental disorders include global delay, speech and language problems, clumsiness, learning disabilities, hyperactivity, and transient behavioural disturbances.

Handicaps and defects are generally characterised by "hard" signs, whereas it is more difficult to define developmental disorders and thus to devise suitable screening procedures. The term intervention encompasses simple advice, treatment, educational activities, and any other form of management that results directly from the professional contact.

\section{Common misconceptions}

A study of the educational and psychological literature shows that many of the implicit assumptions in developmental paediatrics are based on tenuous evidence and that some are incorrect. Thus it is widely believed that parental information about a child's development is unreliable. Retrospective developmental histories are indeed unreliable, ${ }^{6}$ but a description of the child's current abilities is not. Parents may not always understand the importance of what they observe, ${ }^{7}$ but most are good observers. ${ }^{8}$ Furthermore, they are highly accurate detectors of major handicaps.

A second assumption is that delay in achieving milestones indicates abnormality. There are two errors here. Firstly, there is no age at which failure to achieve a skill is abnormal. For example, the distribution curves for the age of achieving walking or talking have very long tails, but most late walkers or late talkers turn out to be normal. . Secondly, and conversely, some children with major handicaps such as cerebral palsy or mental retardation achieve their early milestones within the time designated as normal. ${ }^{10}$ Thus even the most precise developmental testing is no substitute for a physical examination.

A third assumption is that early developmental problems are predictive of later educational failure. Extreme delays in development are usually associated with major handicaps, but milder delays-that is, low developmental scores in the first three years-are only weakly predictive of low IQ or difficulties with learning during the early school years. Severe retardation of language development at age 3, particularly in association with behaviour disorder, indicates a moderately high risk of school failure, ${ }^{11-13}$ as does poor 
performance in neurodevelopmental examinations on school entrance ${ }^{14}$; but in both instances prediction is often wrong in individual cases. When viewed retrospectively over half the children failing in school at age 7 showed normal developmental progress at age $3 .{ }^{15}$ The fundamental dilemma here is that the invention of a perfect screening test, with accurate predictive powers, would imply that the evolution of intelligence is based entirely on genetic factors and is therefore not susceptible to intervention. In fact, a child's development does not proceed along predictable and predestined lines; parents and teachers quite rightly take it for granted that a child will benefit (or suffer) from educational and emotional experiences. ${ }^{16}$

Another false assumption is that many developmental problems are due to deprivation or understimulation and can be helped by the child attending a nursery. Although this assumption is occasionally correct, it is often wrong, damaging, and judgmental and makes parents think that they have failed to rear their child adequately. The assumption is rarely put to the parents in words, but the attitude is conveyed effectively nevertheless. In fact, a nursery is a poor substitute for even a low social class home as far as language development is concerned, though it often provides valuable social experiences. ${ }^{17}$ The results of early stimulation and education programmes for children who are thought to be deprived indicate that: (i) all children (including the deprived, the handicapped, and the privileged) can be taught new skills throughout childhood; (ii) the gains are greater if the parents play a part; and (iii) the gains in IQ are soon lost when the programme of additional stimulation comes to an end. ${ }^{18}$ In some studies, however, there have been small but worthwhile improvements in attitudes to work and in school attainment. Deprived children gain little permanent benefit from early attendance at nursery, because support and encouragement at home are inadequate throughout the school years. These statistical generalisations are based on populations of children whose deprivation varies in severity. They do not exclude the possibility that a small minority of children-for example, those whose mothers are very depressed-may benefit substantially (though it is questionable who is the patient in such cases).

The assumption that development in the first few years of life is critical and particularly susceptible to irreversible damage is untrue except in the case of vision and hearing defects. The effects of even very severe deprivation or understimulation can be reversed as late as 7 or 8 years of age. ${ }^{19}$ The fear of "missing the boat" has lent an unjustified sense of urgency to many aspects of developmental paediatrics.

Finally, the belief that early intervention improves outcome has not been proved. There are several theoretical reasons for believing this to be true in the case of severe hearing ${ }^{20}$ or visual handicaps. ${ }^{21} 22$ Well planned teaching programmes - for example, Portage-designed for the mentally handicapped appear to be effective, though there is no proof that an early start gives better long term results. Early physiotherapy for cerebral palsy has never been shown to improve neurological outcome, though its value in other respects is beyond dispute. ${ }^{23}$ There has been little formal evaluation of programmes to stimulate language at an early age, and their value in improving language delay and preventing later school problems is unknown. ${ }^{24}$ These data are urgently needed to determine the true value of developmental screening for language and global delay.

\section{Detection of developmental problems}

Most major handicaps are first detected in one of three ways: recognition at the routine neonatal or 6 week examination; follow up of an infant at risk because of a neurological insult or family history of handicap; or suspicion of abnormality by parents, relatives, or friends. Less commonly, a general practitioner recognises an abnormality during a consultation for an unrelated problem. Subtle handicaps such as high frequency hearing loss may escape detection in any of these ways, but when parents fail to report more obvious problems they are avoiding a painful truth, are ignorant about normal children, or have previously been given incorrect reassurance.

These observations have six important implications for screening programmes: (i) sensitivity to parental anxieties is essential in all consultations concerning developmental paediatrics; (ii) any surveillance scheme must make full use of the parents' vast store of knowledge about their child: asking parents questions about their children is an effective and efficient form of screening; (iii) sufficient skill must be acquired to permit the detection of subtle handicaps as the more obvious ones will be found by other means; (iv) the abnormalities that are worth seeking at different ages should be clearly specified; (v) the programme must have precise methods of detecting minor defects and developmental disorders as these occur far more commonly than major handicaps; (vi) skilled handling of "difficult" parents is as vital as skill in performing developmental tests.

Detection of major mental and motor handicaps does not usually present any great problem as most cases are recognised in one of the three ways outlined above. Some conditions, however, might occasionally be detected by screening - for example, mild degrees of cerebral palsy, muscular dystrophy, and midline cutaneous abnormalities over the spine often associated with anomalies of the spinal cord.

Sensorineural hearing loss should be detected as early as possible, perhaps eventually by neonatal screening. ${ }^{25}$ In Britain it is established practice to perform a simple screening test of hearing at 8 months of age, but, although potentially reliable, this is often poorly performed and deafness is missed. At present the mean age at diagnosis in many parts of the country is 2 or even 3 years. Diagnosis in the first six months should be the goal and can be achieved by a well directed programme that consists of meticulous training in techniques to test hearing for primary care workers, use of written guidance on hearing responses for parents, rapid response to parental concern, readiness to test all high risk cases, and open access for parents to an audiology clinic. ${ }^{26}$ The 8 month test should be seen as a safety net rather than the main means of detecting loss of hearing.

If most sensorineural losses can be found early in the first year the main yield of the 8 month and subsequent hearing tests should consist of conductive losses caused by secretory otitis media. The possibility of progressive or acquired sensorineural loss must be remembered, but this is rare. The Stycar materials for assessing hearing are now somewhat dated, but modern clinical methods of testing hearing in young children can detect even the modest losses associated with secretory otitis media provided that technique is good and acceptably low levels of background noise can be achieved. The clinical course, age of onset, and degree of loss of hearing associated with secretory otitis media vary considerably, ${ }^{27}$ and therefore fixed ages for screening are of limited value. Parental concern, repeated otitis media, and delayed language development and unexplained behaviour disorder are indications for assessment of hearing. Diagnosis of secretory otitis media calls for constant awareness as well as, or instead of, specific screening tests at fixed times. In some areas, machines measuring acoustic impedance are being used for primary screening, but this technique gives no information about the hearing as it only confirms the presence of dysfunction of the middle ear. Fluid in the middle ear is so common that the technique is of limited value in screening, ${ }^{28}$ and its main value is in the audiology clinic, to show the conductive nature of a hearing loss.

Further research is still needed on many aspects of secretory otitis media, but there can be no doubting its serious effects on development in some children. Surgical treatment certainly restores hearing in the immediate postoperative period, but as the long term results are often less satisfactory careful judgment is needed to select cases in which surgery is justified. Competence in recognising and managing hearing problems should therefore have high priority in developmental surveillance.

Serious visual handicap is usually first recognised by parents or relatives, because either the eyes or the visual behaviour (gaze, fixation, following, etc) of the infant are abnormal. At the 6 week examination inquiry about visual behaviour, simple inspection of the eyes, and a check for cataract ${ }^{29}$ are recommended. Minor defects, however, are very common; refractive errors, squint, and amblyopia occur in up to $10 \%$ of children. Obvious squints and severe myopia are usually noted by parents, and myopia is in any case rare in the preschool years. Detection of less obvious defects, notably small angle squints, hypermetropia, and astigmatism, should therefore be the immediate goal of a screening programme, with the long term aim of allowing development of binocular vision and preventing amblyopia, ${ }^{30}$ rather than detecting it after it has become established. The orthoptic techniques required for detection of small angle squint need considerable skill, and the yield is small when an unselected population of under 2 year olds is screened.

Neither the Stycar graded balls nor the toy test are capable of detecting the mild reduction of visual acuity caused by minor refractive errors. They are widely used in primary screening but were not designed for this purpose; their place is in the assessment of handicapped children. Most children of $21 / 2$ years and upwards can cope with single letter tests, but this method underestimates the severity of amblyopia. The more reliable Snellen line vision chart with a key card can be used if the examination is deferred until the child is a little older.

With existing methods there seems little justification for attempting routine screening of visual acuity in infancy, ${ }^{31}$ but this may be worth while when the clinical course of refractive error is clarified and more precise tests become available. Early referral of any child with the suspicion of a squint is essential. In children of 3 years and upwards an attempt should be made to measure visual acuity for each eye separately as soon as the child is old enough to cooperate with a line vision chart.

The appointment of a community orthoptist to coordinate early detection seems to be successful in promoting rapid diagnosis and treatment without grossly overloading ophthalmic clinics.32

The detection of developmental disorders is the most difficult part of developmental surveillance because of the wide variation in normal development, the difficulties of measurement, the lack of predictive value for future progress, and the uncertain value of intervention..$^{33}$ When parents are already worried that their child might have a disorder they appreciate careful evaluation followed by some form of supportive advice-for 
example, by a physiotherapist-even when the doctors in fact believe the child to be normal. Whether children should be screened for developmental disorders when the parents are not worried is another matter. The main justification for doing so is that a few parents, usually but not exclusively those at the low end of the social scale, fail to recognise not only developmental disorders but even major handicaps in their children. This suggests that those parents who voluntarily bring their children for screening are those who least need to be seen; the main effort should be devoted to those who do not come. Age and sex registers and the computerisation of records of child health are valuable aids to efficient surveillance as the aim must be to survey the entire child population. Surveillance only of high risk children is unsatisfactory as many defects and handicaps occur in children whose family background, obstetric history, and neonatal progress are unremarkable.

Most screening in the United Kingdom is based on the invaluable developmental scales devised by Gesell, Illingworth, and Sheridan, but these lack a standardised method of administration and do not indicate the range of normality. The Denver developmental screening test overcomes these disadvantages and provides a sound basis on which to learn the range of normal child development, ${ }^{34}$ although it is often criticised for being rigid and unimaginative. Several attempts have been made to devise screening tests for abnormal language development, but none has been thoroughly validated. Asking parents about their children is a useful form of screening. Many children are so obviously normal that a formal examination is unnecessary apart from checks of vision and hearing. The Denver prescreening questionnaire can be completed by the parent, health visitor, or nursery nurse and is an economical approach to screening that has not yet been explored adequately in the United Kingdom. ${ }^{3}$

Most children undergo a further time consuming developmental examination on entry to school, with a view to anticipating possible learning problems. Although the aim is to help teachers to use their resources more effectively, many leading educationalists have argued for some years that continued responsiveness to a child's educational needs is more important than a single examination. ${ }^{36}$

Screening for physical disorders includes monitoring of height, weight, and head circumference; detection of congenital dislocation of the hip, heart disease, coarctation, and undescended testicles; and advice about minor orthopaedic problems. We will not discuss these disorders here, but even these apparently simple matters are not free from controversy, and there are plenty of pitfalls for the poorly trained.

In conclusion, many abnormalities can be detected by listening to parents and asking appropriate questions about vision, hearing, and developmental progress. Minor defects of hearing and vision probably justify a formal screening programme in all districts, but high standards must be maintained. Techniques, training methods, diagnostic criteria, and referral pathways should be agreed for a whole community.

Some districts and general practices may aim to screen all children for developmental disorders using either an unstandardised procedure or a formal screening test. Others will consider it to be more cost effective to test only selected children, relying on parental awareness for the remainder. Whichever approach is adopted, precise pass-fail endpoints are artificial and dangerous; the interpretation of any developmental information requires knowledge and experience that can be gained only by seeing many children from a variety of social backgrounds.

Much of the primary screening, including physical examination, could be done by health visitors, provided that staffing levels are adequate; the health visitors are allowed to concentrate on this part of their job; and training, support, and supervision are provided, preferably by a consultant community paediatrician. It is not surprising that there is little agreement on the optimal ages or methods for developmental surveillance. The suggested "best buy" programme (table) is based on an appraisal of the target disorders for which screening may be useful at various ages and also recognises the reality that at present experienced clinical medical officers are more numerous than well trained health visitors.

\section{Philosophical implications}

Surprisingly little has been written in the United Kingdom about the ethics of screening. In checking the development of a child whom the parent imagines to be normal the doctor is making several assumptions that are not always justified, as discussed above. In effect, the parents are offered a contract whereby developmental problems are detected and remedied or normality is confirmed, but they do not appreciate that the doctor might be unable to provide the answers or even occasionally gives the wrong ones. If they reject this contract they are liable to be designated bad parents. More disturbing is the widespread practice of screening children in day nurseries without their parents being present; sometimes the parents are not even informed until after the event. Unquestionably, society always has a right and duty to protect its children from cruelty and poverty, but
System of developmental surveillance

\begin{tabular}{|c|c|c|c|}
\hline $\begin{array}{l}\text { Age of } \\
\text { child }\end{array}$ & $\begin{array}{l}\text { Children to } \\
\text { be examined }\end{array}$ & Procedure & $\begin{array}{l}\text { Person performing } \\
\text { surveillance }\end{array}$ \\
\hline Newborn & All & $\begin{array}{l}\text { Physical examination: inspect eyes; } \\
\text { check red reflex (hearing screening } \\
\text { test??) }\end{array}$ & Paediatric house staff \\
\hline $\begin{array}{l}\text { First home } \\
\text { visit }\end{array}$ & All & $\begin{array}{l}\text { Give parents hearing and vision } \\
\text { checklists; instruct parent about } \\
\text { access to local services }\end{array}$ & Health visitor \\
\hline At any age & If parent worried & Referral to appropriate service & $\begin{array}{l}\text { General practitioner or } \\
\text { clinical medical officer }\end{array}$ \\
\hline $\begin{array}{r}\text { First six } \\
\text { weeks }\end{array}$ & All & $\begin{array}{l}\text { Physical examination: eyes, as neonate, } \\
\text { and observe visual behaviour. Ask } \\
\text { parents about vision and hearing }\end{array}$ & $\begin{array}{l}\text { General practitioner or } \\
\text { clinical medical officer }\end{array}$ \\
\hline 3 Months & All & Hips & $\begin{array}{l}\text { General practitioner or } \\
\text { clinical medical officer }\end{array}$ \\
\hline 8 Months & All & $\begin{array}{l}\text { Physical examination: Denver } \\
\text { developmental screening test; } \\
\text { distraction test of hearing; inspect } \\
\text { eves; cover test for squint; observe } \\
\text { visual behaviour }\end{array}$ & $\begin{array}{l}\text { General practitioner or } \\
\text { clinical medical officer }\end{array}$ \\
\hline $\begin{array}{l}2 \text { Years } \\
3 \text { months }\end{array}$ & All & $\begin{array}{l}\text { Informal observation at home or } \\
\text { nursery. Structured developmental } \\
\text { and behavioural questionnaire: strict } \\
\text { referral criteria }\end{array}$ & Health visitor \\
\hline $31 / 2$ Years & All & $\begin{array}{l}\text { Physical examination: height; weight; } \\
\text { hearing (McCormick toy test); } \\
\text { otoscopy; ision-linear chart (each } \\
\text { eye, separately); Denver } \\
\text { developmental screening test or } \\
\text { similar. Behaviour checklist }\end{array}$ & $\begin{array}{l}\text { General practitioner or } \\
\text { clinical medical } \\
\text { officer, community } \\
\text { orthoptist, or speech } \\
\text { therapist }\end{array}$ \\
\hline $\begin{array}{l}\text { School } \\
\text { entry }\end{array}$ & (i) All & $\begin{array}{l}\text { Physical examination; hearing and } \\
\text { vision }\end{array}$ & $\begin{array}{l}\text { Clinical medical officer } \\
\text { or school nurse }\end{array}$ \\
\hline $\begin{array}{l}\text { School } \\
\text { entry }\end{array}$ & $\begin{array}{l}\text { (ii) Parental } \\
\text { concern, history } \\
\text { of developmental } \\
\text { problem }\end{array}$ & $\begin{array}{l}\text { Neurological and developmental } \\
\text { examination; psychiatric or } \\
\text { psychological referral if required }\end{array}$ & Clinical medical officer \\
\hline $\begin{array}{l}\text { Any time in } \\
\text { school }\end{array}$ & $\begin{array}{l}\text { (iii) Parental } \\
\text { concern, history } \\
\text { of developmental } \\
\text { problem, worried } \\
\text { teacher }\end{array}$ & $\begin{array}{l}\text { Neurological and developmental } \\
\text { examination; psychiatric or } \\
\text { psychological referral if required }\end{array}$ & Clinical medical officer \\
\hline
\end{tabular}

intervention in developmental problems without parental cooperation can rarely be justified. The morality of inflicting on other social and ethnic groups the assumptions of white middle class professionals about what constitutes optimal child rearing and the achievement of potential can also be questioned. In many families the exact attainment of milestones at particular ages is less important than a mismatch between the child's actual abilities, his parents' expectations, and the appropriateness of the experiences provided for him. In other words, it is as important to know the parents and their social circumstances as it is to assess the child. It may be harmful to urge parents to accept help when they do not perceive any problem.

\section{Problems of management}

The general practitioner and clinical medical officer must know when, how, and to whom a referral should be made when an abnormality is suspected. They should know what services can reasonably be expected and should understand the behaviour and feelings of parents who have an abnormal child.

When parents themselves suspect an abnormality they are likely to be right, and usually referral to specialist services rather than the use of a screening test is the appropriate response. Abnormalities suspected on screening tests are more problematic; explanation and discussion are often necessary, and parents should rarely be pressurised into accepting referral, as very few developmental problems are urgent. Indeed, the skills needed to persuade parents that there may be something wrong with their child are akin to those needed to set up a psychiatric referral. Developmental surveillance also provides an opportunity to discuss problems of parentchild relationships and child rearing, but some familiarity with modern child psychiatry, behavioural techniques, and the problem of non-accidental injury is essential.

Before starting any developmental programme the doctor should acquaint himself fully with local services. He should have at his fingertips the names, addresses, and telephone numbers of the relevant consultants and therapists, the community orthoptist, the educational psychologist, and the social worker who deals with handicap, and he should know how each sees his or her role in that particular community. Ideally, he should visit the nearest child development centre and meet members of the district handicap team. He can reasonably expect certain services to be provided for any child with a handicap and should ensure that the parents are receiving them. These services include a rapid response to referral; a precise diagnosis; counselling on the handicap itself and on its genetic background; a verbal and written explanation of the problem; advice on help available for the child-namely, management, local services, national voluntary societies, financial help, respite care, dental care, immunisation, the Education Act, and equipment; an introduction to therapists, psychologists, social workers, and educational services; and long term follow up. 
Lastly, the doctor must understand how the parents of a handicapped child pass through psychological processes of mourning and adjustment, which often lead to a variety of maladaptive behaviours and unnecessary secondary handicaps in the child ${ }^{37}$; they may also give rise to non-organic complaints in the parents and siblings. The general practitioner is in a unique position to deal with these.

\section{Conclusion}

The exact place of developmental screening in primary care remains a matter for debate, as does the division of labour between the general practitioner, the clinical medical officer, and the health visitor. We suggest, however, that every general practitioner needs some knowledge of developmental paediatrics as outlined here and can practise effective surveillance, even if he does not intend to introduce a formal screening programme.

\section{References}

1 Wilson JMG, Jungner G. Principles and practice of screening for disease. Public Health Pap $1968 ;$ No 34 .

2 Cochrane AL, Holland WW. Validation of screening procedures. Br Med Bull 1971;27:3-8.

3 Rose G. Epidemiology for the uninitiated; screening. Br Med f 1978;ii: 1417-8.

4 Holt KS. Developmental screening of children. Lancet 1974;ii: 1057-61.

5 World Health Organisation. International classification of impairments, disabilities and handicaps; a manual of classification relating to the consequences of disease. Geneva: WHO, 1980.

6 Hart H, Bax M, Jenkins S. The value of a developmental history. Dev Med Child Neurol 1978;20:442-52.

7 Newson E. Parents as a resource in diagnosis and assessment. Early management of handicapping disorders. IRMMH Review of Research and Practice 1976;19:105-17.

8 Frankenburg WK, Camp BW, Van Natta PA, Demersseman JA, Voorhees SF. Reliability and rankenburg WK, Camp BW, Van Natta PA, Demersseman JA, Voorhees SF. Rel
stability of the Denver developmental screening test. Child Dev 1975;42:1315-25.

9 Chaplais J de Z, Macfarlane JA. A review of 404 'late walkers.' Arch Dis Child 1984;59:512-6.

10 Neligan G, Prudham D. Potential value of four early developmental milestones in screening children for increased risk of later retardation. Dev Med Child Neurol 1969;11:423-31

11 Fundudis T, Kolvin I, Garside RE, eds. Speech retarded and deaf children: their psychological development. London: Academic Press, 1979.

12 Richman N, Stevenson J, Graham P. The relationship between language development and behaviour. In: Schmidt MH, Remschmidt $\mathrm{H}$, eds. Epidemiological approaches in child psychiatry II. New York: Thieme-Verlag, 1983:57-69.

13 Silva PA, McGee R, Williams S. A follow up study of the prevalence and stability of language delay from three to seven years of age and its significance for seven year low intelligence and reading difficulties. Deo Med Child Neurol 1983;25:783-93.

14 Bax M, Whitmore K. Neurodevelopmental screening-the school entrant medical examination. Lancet 1973;ii:368-70.

15 Drillien C, Drummond M. Developmental screening and the child with special needs. London: Heinemann, 1983. (Clinics in Developmental Medicine No 86.)

16 Wedell K, Lindsay GA. Early identification procedures: what have we learned? Remedial Education 1980;15:130-5.

17 Tizard B, Hughes M. Young children learning. London: Fontana, 1984

18 Clarke MM, Cheyne WM. Studies in pre-school education. Sevenoaks: Hodder and Stoughton Educational, 1979.

9 Skuse D. Extreme deprivation in early childhood. II. Theoretical issues and a comparative review f Child Psychol Psychiatry 1984;25:543-72.

20 Brugge JF. Development of the lower brainstem auditory nuclei. In: Romand R, ed. Developmen of auditory and vestibular systems. New York: Academic Press, 1983:111-4.

21 Eggers HM, Blakemore C. Physiologic basis of anisometropic amblyopia. Science 1978;201:264-6.

22 Sonksen PM. Visual handicap and development. In: Wybar K, Taylor D, eds. Paediatric ophthalmology. New York: Marcel Dekker, 1979:85-95

23 Wright T, Nicholson J. Physiotherapy for the spastic child-evaluation. Dev Med Child Neurol 1973;15:146-60.

24 Harris J. Early language intervention programmes-an update. Newsletter of the Association for Child Psychology and Psychiatry 1984;6(2):2-20.

25 Bhattacharya J, Bennett MJ, Tucker SM. Long term follow up of newborns tested with the auditory response cradle. Arch Dis Child 1984;59:504-11.

26 McCormick B, Wood SA, Cope Y, Spavins FM. Analysis of records from an open access audiology service. Br $\mathcal{f}$ A udiol 1984;18:127-32.

27 Sade J. Secretory otitis media and its sequelae. Edinburgh: Churchill Livingstone, 1974. (Monographs in Clinical Otolaryngology No 1.)

28 Advisory Committee on Services for Hearing Impaired People. Report. London: DHSS, 1981.

29 Taylor D, Rice NSC. Congenital cataracts, a cause of preventable child blindness. Arch Dis Child 1982;57:165-7.

30 Ingram RM. The possibility of preventing amblyopia. Lancet 1980;i:585-7.

31 Hall SM, Pugh AG, Hall DMB. Vision screening in the under-5s. Br Med f 1982;285:1096-8.

32 Smith V, Keen J. Visual handicap in children. London: Heinemann, 1979. (Clinics in Developmental Medicine No 73.)

33 Hall DMB. The child with a handicap. Oxford: Blackwell Scientific Publications, 1984.

34 Frankenburg WK, Sciarillo W, Burgess D. The newly abbreviated and revised Denver screening test. F Pediatr 1981;99:995-9.

35 Frankenburg WK, van Doorninck WJ, Lidell TN, Dick NP. The Denver pre-screening developmental questionnaire (PDQ). Pediatrics 1976;57:744-53.

36 Leach DJ. Early screening for school learning difficulties: efficacy, problems and alternatives. Occasional Papers of the Division of Educational and Child Psychology 1981;5(2):46-59. (British Psychological Society.)

37 Bicknell J. The psychopathology of handicap. Br J Med Psychol 1983;56:167-78.

(Accepted 25 May 1985)

\section{MATERIA NON MEDICA}

\section{A drink with a difference}

The knife blade that we removed from his stomach was ten inches long. It had severely injured his oesophagus, and he had to be fed through a gastrostomy tube. He relished neither the idea nor the food but religiously followed our strict instructions of not taking anything by mouth. Every day he would ask us, "When will I be able to eat and drink?" We had no reply to his query. He was too weak to withstand the major operation that was required to replace his injured oesophagus. We told him it would not be possible till he gained some weight and his general condition improved. From that day onwards he would instil anything that he could into his gastrostomy tube and would weigh himself at least twice a day and maintain a meticulous record of his weight.

But as (bad) luck would have it, he had an attack of intestinal obstruction, which caused us much anxiety as he was not in a condition to undergo an operation-but there was no choice. The operation made him lose some more weight. We were prepared to fight the battle, however, and so was he. He was given a highly nutritious diet, and our efforts soon started showing results. One day he happily announced to us, "Doctor, I am $40 \mathrm{~kg}$ today." That was our target when we started.

Three teams operated simultaneously - one in the abdomen, the second in the chest, and the third in the neck-to replace his oesophagus. Surprisingly, he had an uneventful recovery and was up and about in a few days.

Then came the moment all of us were anxiously waiting for-the day his neo-oesophagus was to be radiologically evaluated. Our joy knew no bounds as we saw on the screen the barium paste that he swallowed going down through the newly constructed oesophagus.

Smiles of joy spread across all the faces as the successful results of the $x$ ray examination were announced.

"Can I eat and drink now?" he asked.

"Yes, certainly. What would you like to have-orange juice, milk, tea, or coffee?"

Ignoring all suggestions, he got up from the bed, moved to the cupboard beside him, took out a glass, and poured into it what he wanted most to drink and had not been able to for months—-water.—VINAY KUMAR KAPOOR, New Delhi, India.

\section{Two's company, three's a crowd}

We live in an age of the travelling specialist, well illustrated in the novels of Malcolm Bradbury and David Lodge. Those of us in the medical profession are not immune to this need to travel and do so with as much alacrity as our other colleagues in literature, the sciences, and so on. As well as broadening the mind, travelling and working in foreign countries far from the familiar work environment can lead to an appreciation that perhaps one's work habits are not quite as smooth as perceived.

Interplast, Inc is an organisation that provides free plastic surgery to indigenous people in many countries of the world. Teams of surgeons, nurses, and anaesthetists travel from the United States and spend anything from a few days to a few weeks operating on cleft lips and palates, doing reconstructive burn surgery, and so on, in the local community hospitals to which they are invited.

It is not unusual for the medical team to be accompanied by a journalist from some American publication. The Interplast programme is unique in that residents are included as an integral part of the medical team. On this occasion our friendly photojournalist asked permission to see and record an anaesthetic induction being performed on a small child. The anaesthesia team, resident and attending, used to flowering unseen, was flattered and readily agreed. Forgotten was the old proverb, "Pride goeth before destruction and an haughty spirit before a fall." On went the mask, readily accepted by the small patient, and sleep was speedily induced. Paralysis followed smoothly. Laryngoscope was poised for the intubation, the resident called for his tube-his voice ascending in scale as unfortunately no endotracheal tube could be found. There followed an undignified, but happily short, period of searching in and around the operating table, followed by a triumphant cry as the endotracheal tube was found, hastily cleaned, and restored to its rightful place in the small patient's trachea. All this was closely watched by our journalist colleague. "Now," he said to me, "I understand why it takes two of you to give anaesthesia."-STANLEY SAMUELS, associate professor of anaesthesia, Stanford, California. 